\title{
Desenvolvimento de um Software para Auxílio na Comunicação de quem tem Transtorno do Espectro Autista - TEA
}

\author{
Julia Ribeiro Doria \\ Ciência e Tecnologia \\ Inst. Federal de Mato Grosso do Sul \\ Campo Grande, MS, Brasil \\ jrdoria9@gmail.com \\ Paulo Azuaga Braga \\ Ciência e Tecnologia \\ Inst. Federal de Mato Grosso do Sul \\ Campo Grande, MS, Brasil \\ paulo.braga@ifms.edu.br
}

\author{
Mariana Cavalcante Lopes \\ Ciência e Tecnologia \\ Inst. Federal de Mato Grosso do Sul \\ Campo Grande, MS, Brasil \\ marianacavalcante33@gmail.com \\ Adair da Silva Oliveira Junior \\ Ciência e Tecnologia \\ Inst. Federal de Mato Grosso do Sul \\ Campo Grande, MS, Brasil \\ adair.oliveira@ifms.edu.br
}

\begin{abstract}
Autistic Spectrum Disorder - TEA is marked by a number of characteristics that influence the daily lives of citizens with the disorder. This change consists of difficulty in communicating with society, badly social interaction and restricted and repetitive behavior, of- ten not dealing with changes in routine. Due to these obstacles faced by autists, forms of intervention arise in order to social inclusion towards these people, such as alternative methods that help autistics communicate. The Picture Exchange Communication System - PECS is one of these assistive tools, based on picture communication, one simulates autism and others everyday foods and objects. However, this method has some issues, for example, some of them cannot associate an illustrative figure that represents an object in reality, causing the PECS to be unusable. From this, this project based on the development and implementation of the site "SeuPecs", based on the above Communication System, with the creation of unique PECS for each autistic in order to contribute to the communication of who has the TEA.
\end{abstract}

\section{KEYWORDS}

TEA, Interação Social, Métodos Alternativos, PECS

\section{INTRODUÇÃO}

Com o alto desenvolvimento tecnológico, principalmente na área da saúde, originaram-se diversas pesquisas sobre o Transtorno do Espectro Autista - TEA, uma delas do Centers for Disease Control and Prevention - CDC, o qual levantou dados no ano de 2017 e foi estimado que $1 \%$ da população (aproximadamente 70 milhões de pessoas) possui o TEA e que em homens é quatro vezes mais prevalente o aparecimento do transtorno do que nas mulheres [1].

O médico austríaco Leo Kanner realizou um estudo em 1943, a base dele foram onze crianças que apresentavam algumas particularidades em comum, como a incapacidade de se relacionarem com os outros, graves distúrbios de linguagem (tendo dificuldade para se expressarem verbalmente) e uma rígida e restrita rotina, ou seja, não gostavam de mudanças, então esse médico denominou essas características como autismo infantil precoce [2].

O transtorno abordado neste projeto possui diferentes comportamentos explicitados por um distúrbio no desenvolvimento neurológico conhecido como tríade, que são capazes de se manifestar sentar dificuldade em sua comunicação pela deficiência no controle da fala, uma precária socialização e demonstração de comportamento restritivo e repetitivo, normalmente, não conseguindo lidar com mudanças de rotinas [3].

Tendo em vista as dificuldades que as pessoas com alguma deficiência possuem para se comunicarem foi desenvolvida a Comunicação Alternativa e Ampliada - CAA que se origina como um meio de auxiliar a incapacidade de se comunicar desses indivíduos. Existem diversos tipos de CAAs, um dos exemplos são o BlissSymbolics, Picture Communication Symbols (PCS) e o PECS [4].

Tem-se como alvo de estudo a abordagem do Picture Exchange Communication System - PECS, em português, Sistema de Comunicação por troca de figuras. Esse método alternativo é um livro composto de figuras ilustrativas de objetos e comidas do cotidiano, no qual com a ajuda de um responsável é montado frases do que o autista deseja no momento e assim é possível estabelecer a comunicação com a sociedade [5].

Algumas pessoas com TEA não são capazes de manusear o PECS por diversos motivos, para alguns autistas a metodologia não é atrativa, a maioria possui dificuldade de interação social, como descrita por [5]: "uma criança autista percebe o mundo ao redor de forma diferente, tendo dificuldades qualitativas em sua interação social [...]", além do PECS não ser prático, já que é um livro composto por muitas figuras manuseadas constantemente sendo necessário alguém para auxiliar na utilização, dentre outras dificuldades. 
Como as pessoas com o TEA possuem uma larga escala de dificuldade com a utilização do PECS e também que a cada dia a tecnologia torna-se mais presente na vidas de todos, este trabalho fundamenta-se na possibilidade da melhora da comunicação e da interação social destes indivíduos por intermédio de um software que utiliza como base o sistema de tratamento alternativo - PECS.

\section{METODOLOGIA}

A partir de pesquisas feitas em diversos trabalhos sobre o TEA além de verificar algumas plataformas já existentes que possuem o objetivo de auxiliar na comunicação desses indivíduos, este trabalho baseou-se no site Niki Talk, cujo qual é uma plataforma desenvolvida com finalidade semelhante a nossa e possui a mesma sistemática do PECS supracitado com a viabilidade da inserção de áudio, ou seja, fundamenta-se no método alternativo PECS aplicando a metodologia assistiva digitalmente com a utilização de figuras ilustrativas. Tendo isso em vista, este projeto diferencia-se no desenvolvimento de uma ferramenta com acesso privado seguido da criação de um PECS personalizado para cada autista.

O início do projeto consistiu na realização e aplicação, respectivamente, de uma entrevista semiestruturada e um questionário, ambos com a professora e os pais de quem tem filhos com o TEA - considerando a dificuldade de comunicação deste público -, no intuito da obtenção de dados a fim da execução das etapas seguintes e principalmente do desenvolvimento do site. Para a efetivação desses dois processos obteve-se a ajuda de uma Instituição especialista no transtorno localizada em Campo Grande - MS, a Associação de Pais e Amigos do Autista - AMA.

A entrevista baseou-se em perguntas estruturadas, como, problemas presentes no cotidiano das pessoas com o TEA, exemplos de situações difíceis de que os pais já passaram com seus filhos, sobre os métodos alternativos e a utilização destes, para assim nos ambientarmos no contexto social/educacional deles. Já o questionário fundamentou-se de questões objetivas e dissertativas que visavam o recolhimento de dados associados às relações dos indivíduos autistas com amigos e familiares, a rotina de cada um, a tecnologia e a importância dela no dia a dia deles, entre outras.

Como foi averiguado, o PECS possui alguns empecilhos e por isso muitos autistas não o utilizam, com isso, a nossa proposta surgiu como possibilidade de aprimoramento do PECS existente e da relação deste com a tecnologia. Com base nisso, na análise dos requisitos obtidos, dos resultados da entrevista semiestruturada e do questionário deu-se início a programação do software, o qual se finda na implementação de um site que utiliza fotos de objetos pessoais dos indivíduos com o TEA para facilitar a associação destas com a ações a serem realizadas por eles.

$\mathrm{Ou}$ seja, a plataforma tem como funcionalidade principal a construção de um PECS exclusivo para cada autista que utilizar a plataforma. Vale ressaltar também que esses PECS personalizados são focados em três áreas: lazer, escolarização e alimentação, sendo esta última dividida em comer e beber com a presença de subitens para uma melhor organização dos alimentos. Por exemplo, a área comer possui subitens como: refeição, frutas, etc. Esses tópicos foram escolhidos em virtude de estarem mais presentes no cotidiano dos cidadãos atrelado a característica da tríade, o comportamento restrito e repetitivo dos autistas necessitando de uma maior e melhor organização nesses campos.

O site contém a possibilidade da inserção de áudio através do upload destes previamente gravados pelo responsável com a intenção dos PECS exclusivos disporem de uma voz familiar. Este será ativado por meio do clique do mouse na montagem das frases e posteriormente na frase final, pois como a oralização é um dos problemas para os indivíduos com o TEA e alguns não são alfabetizados ao ouvir o áudio, por meio da repetição, o autista com o tempo passa a associar a imagem com o áudio e a legenda, assim estimulando a fala.

Em paralelo ao desenvolvimento do site foi feito um acompanhamento com a professora especialista no transtorno para melhor adequamento tanto na estética da plataforma, envolvendo cores, tamanho de fontes, imagens, legendas, entre outros quanto nas funcionalidades presentes na ferramenta - login, upload de fotos, ações dos usuários, dentre outras -.

A ferramenta foi desenvolvida em três linguagens principais sendo elas: HTML, PHP e JavaScript com banco de dados MySQL e assim constituída de 6 páginas principais de fácil acesso pelo menu localizado na parte superior da tela, sendo: a primeira opção a página onde automaticamente o site dá entrada, nela possui uma breve mensagem de acolhimento e explicação da plataforma. A segunda possibilidade de escolha é um informativo sobre o que é o PECS, qual a funcionalidade dele e o principal objetivo desse método alternativo para aqueles usuários que não possuem o conhecimento dessa metodologia assistiva. Na terceira opção do menu é uma página explicando a equipe de desenvolvimento e o que o software faz.

Já na quarta corresponde a uma página, na qual o usuário pode entrar em contato com os administradores do site em caso de dúvidas ou problemas com a ferramenta. O site possui como penúltima opção um exemplo de PECS demonstrativo nas três áreas abordadas para aqueles pais que não possuem uma noção concreta sobre os PECS exclusivos e também para melhor entendimento tanto sobre o PECS em si quanto sobre a ideia de funcionamento da nossa plataforma.

E como última possibilidade, os pais poderão criar um PECS personalizado para uma pessoa com o TEA, todavia a construção de um PECS exclusivo para o autista só será realizada após o cadastro na plataforma, ou seja, usuário deverá criar um perfil e assim realizar o upload de fotos de cada área e subitem (comer frutas, lanches, etc) e das respectivas legendas. Para maior conforto tanto dos pais quanto dos autistas, o responsável pode deixar a plataforma salva com o perfil aberto e também nos favoritos.

Para melhor entendimento das funcionalidades do site, algumas telas estão presentes nas Figuras 1 e 2. 


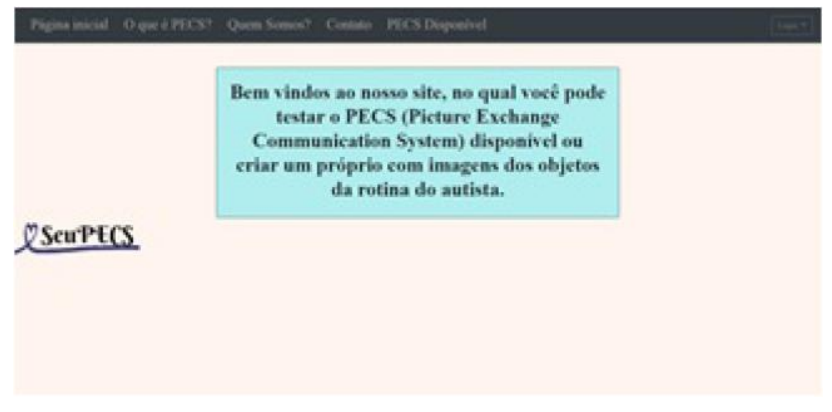

Figure 1. Tela Principal. Fonte: Autoras.

Já para a realização mais minuciosa quanto ao software, suas funcionalidades e adequações mais satisfatórias ao nosso público alvo, pessoas com o TEA, o projeto sucedeu-se com a execução de uma etapa referente a um dos testes da plataforma, ou seja, foi desenvolvido um PECS exclusivo para um autista participante das primeiras etapas (entrevista semiestruturada e do questionário) dividido nas áreas supracitadas. Essa fase do trabalho fundamentou- se em sucessivas reuniões com a mãe do autista para o recolhimento das fotos dos objetos pessoais do autista para a construção do PECS.

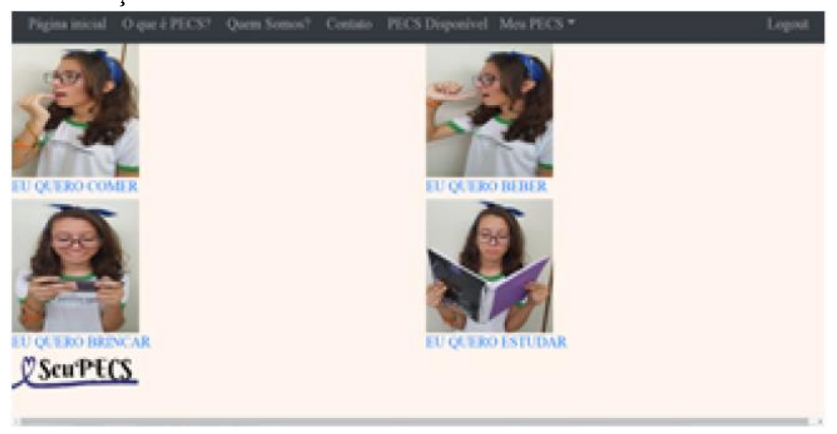

Figure 2. PECS Disponível. Fonte: Autoras.

Posteriormente a formação do PECS para esse indivíduo em específico, está sendo realizada a utilização, adaptação e imersão do PECS virtual e exclusivo na vida do jovem como o novo método de comunicação deste. A habituação está sendo de forma lenta e gradual, primeiramente, a ferramenta encontra-se implantada no ambiente familiar, devido a uma das características da tríade, o comportamento restrito e repetitivo, todavia, futuramente, pretende-se ampliar para o ambiente escolar. Após a adaptação da plataforma neste jovem com o transtorno e aos resultados, será realizado um teste com a comunidade de pais com filhos autistas na AMA com o intuito de expandir os nossos resultados tanto ao desempenho, detalhamento e estética do software quanto para a ampliação dos usuários na utilização do site como ferramenta de auxílio na comunicação e interação social de quem tem o TEA.

\section{RESULTADOS E ANÁLISES}

Com a entrevista semiestruturada realizada na instituição de apoio, obteve-se dados que mostraram a dificuldade na comunicação e interação do autista com a sociedade. Vale ressaltar que uma mãe expressou o quão precário é a comunicação dos autistas por meio de uma vivência com o filho, um dia ele estava com muita dor, mas não conseguia transmitir para a mãe onde era a dor.

Juntamente com os dados anteriores, enfatizou-se que um dos filhos dos entrevistados não utiliza o PECS pela falta de atratividade e também devido à grande dificuldade em relacionar a figura ilustrativa contida no PECS com objetos da vida real impossibilitando o uso dessa metodologia.

A partir do questionário alcançou-se dados que comprovaram a boa relação familiar com o autista, que eles possuem facilidade e se sentem atraídos com a tecnologia. Notou-se que os principais meios de comunicação utilizados por quem tem TEA são gestos e ecolalias - os quais têm como característica principal a repetição de frases e/ou palavras ditas por outras pessoas -, além de ter sido relatado que somente um autista se comunica por um método alternativo de comunicação.

Com isso, percebe-se que os autistas são distintos entre si, assim como diz [6]: "às particularidades do transtorno variam de acordo com o desenvolvimento cognitivo. Pessoas com TEA podem apresentar grave deficiência intelectual, sem o desenvolvimento da linguagem, com padrões repetitivos simples, e também com diagnósticos completamente distintos".

\section{CONSIDERAÇÕES FINAIS}

A plataforma encontra-se na primeira fase de teste, a partir deste, já nota-se uma melhora na comunicação do autista com os pais, além de uma maior autonomia nas escolhas rotineiras dentre as três áreas supracitadas. A ambientação está ocorrendo de forma gradual devido a uma das características da tríade, o comportamento restrito e repetitivo. Como esse teste está sendo em função do autista da entrevista semiestruturada, a novas mudanças na plataforma, como a inserção de novas áreas e subitens está sendo efetuada conforme a necessidade desse autista na utilização do PECS exclusivo.

Seguidamente, pretende-se ampliar a pesquisa para a comunidade externa de pais com filhos autistas na instituição de apoio com o intuito de averiguar tanto na estética e funcionamento do site quanto no auxílio deste para com os autistas. Com isso, espera-se que o software seja a ponte de comunicação entre o autista e a sociedade e se necessário o aprimoramento do site para que mais pessoas com o transtorno possam ter um suporte de fácil acesso, assim auxiliando cada vez mais a comunicação do autista com a sociedade e consequentemente a interação social de cada um.

Almeja-se que a plataforma possa auxiliar na tríade supracitada, conclui-se também que com a utilização da ferramenta, esta possa permitir aos autistas um maior controle nas rotinas e que os pais e/ou responsáveis consigam ter uma maior simplicidade na organização/comunicação geral desses indivíduos 
XI Computer on the Beach

2 a 4 de setembro de 2020, Baln. Camboriú, SC, Brasil

Doria et al.

com o transtorno. A partir da junção do PECS com a tecnologia, ansiamos que esta seja usada para algo benéfico, próspero e positivo a eles com resultados proveitosos e gradativos e que assim, o site possa simplificar a forma de expressar das pessoas que possuem o transtorno e melhorar a qualidade de vida desses cidadãos.

\section{REFERÊNCIAS}

[1] Karina Griesi-Oliveira and Andréa Laurato Sertié. Autism spectrum disorders: an updated guide for genetic counseling. Einstein (São Paulo), 15:233 - 238, 06 $2017 . \quad$ ISSN $1679-4508 \quad$ URL http://www.scielo.br/scielo.php?script=sciarttext\&pid=S1679$45082017000200233 \&$ nrm=iso.

[2] Cleonice Bosa and Maria Callias. Autismo: breve revisão de diferentes abordagens. Psicologia: Reflexão Crítica, 13:167 - 177, 00 2000. ISSN 01027972. URL http://www.scielo.br/scielo.php?script=sci_arttext\&pid=S0102$79722000000100017 \&$ nrm $=$ iso.

[3] Eugênio Cunha. Autismo e inclusão psicopedagogia e práticas educativas na escola e na família. WAK, Rio de Janeiro, 3 edition, 2011.

[4] Marcela de Guastalli and Suélen Takahama. Comunicação alternativa: acessibilidade comunicativa e recursos que possibilitam a inclusão do aluno com deficiência. Revista Alterjor, 7(1):1-14, jun. 2013. URL http://www.revistas.usp.br/alterjor/article/view/88282.

[5] Cinthya Raquel de Moura Sousa. Niki talk: Uma tecnologia assistiva para a comunicação de crianças autistas. In Anais III CONEDU, Campina Grande, 2016.

[6] Jeane Figueiredo. O Autismo Infantil: uma revisão bibliográfica, 2015. Trabalho de Conclusão de Curso. São Luís, MA. 